\title{
Tuberous sclerosis with rare presentation of macrodactyly
}

\author{
Ho-En Tung • Shin-Lin Shih
}

Received: 12 December 2008 / Revised: 19 January 2009 / Accepted: 2 February 2009 / Published online: 5 March 2009

(C) Springer-Verlag 2009

An 11-year-old boy was diagnosed with tuberous sclerosis (TS). He also had swelling of his right thumb and radial aspect of his right wrist (Fig. 1). A radiograph of the right hand (Fig. 2) showed irregular periosteal new bone formation (arrow) involving the first metacarpal bone, the radial aspect of the second proximal phalangeal bone, and the first proximal and distal phalangeal bones. Cortical cysts were also noted (arrowhead). A soft-tissue lump was seen involving the right thumb and radial aspect of the wrist. Both T1- and T2-W MR images of the hand showed low signal intensity. This suggested that the lesion was composed of fibrous tissue.

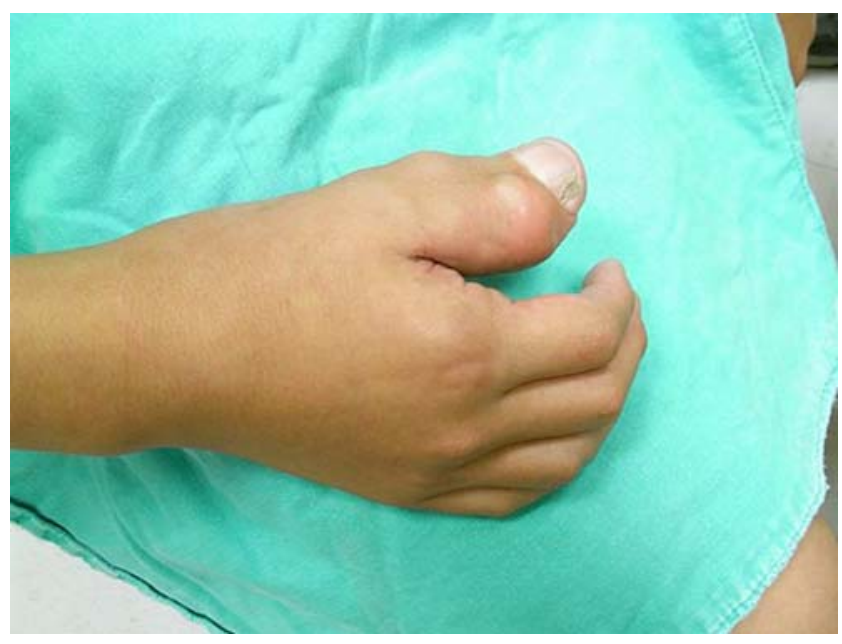

Fig. 1 Photograph of the right hand

\section{H.-E. Tung $\cdot$ S.-L. Shih}

Department of Radiology, Mackay Memorial Hospital, 92, Sec. 2, Chung-Shan N. Rd.,

Taipei, Taiwan 104

\section{H.-E. Tung}

Mackay Medicine, Nursing and Management College,

Taipei, Taiwan

\section{S.-L. Shih $(\square)$}

Department of Radiology, Taipei Medical University,

Taipei, Taiwan

e-mail: liupon@pchome.com.tw

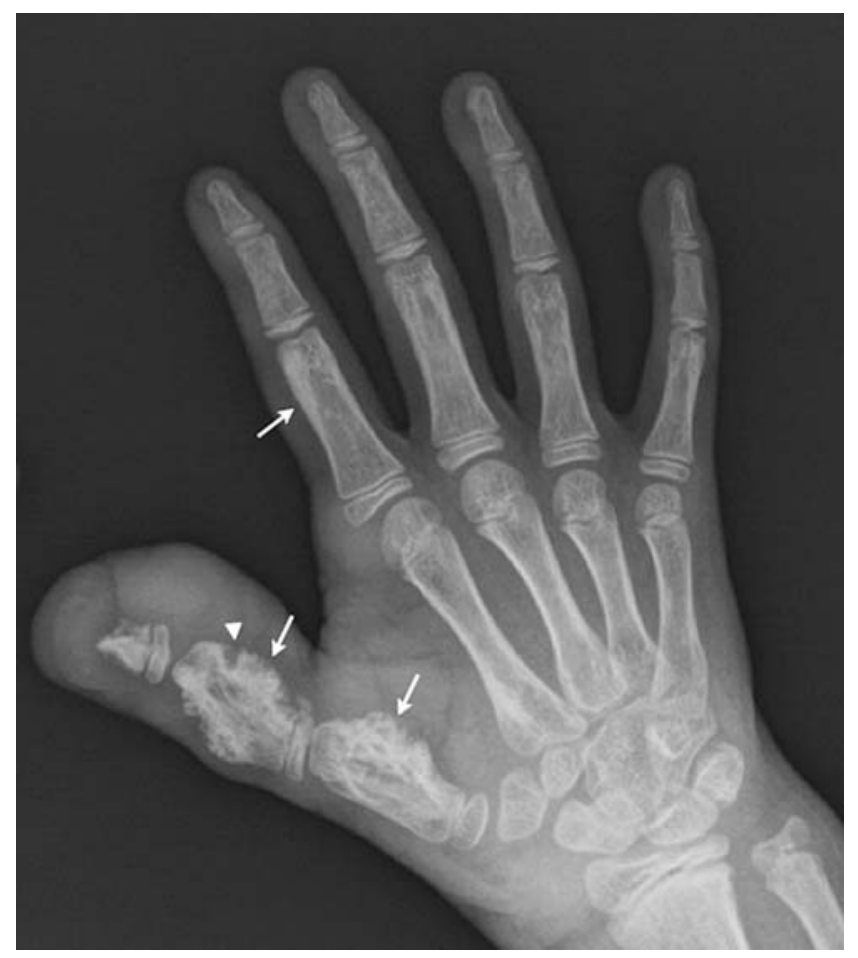

Fig. 2 Radiograph of the right hand

TS is a multisystem disorder with osseous manifestations in the spine, the pelvis and commonly the calvaria, and short tubular bones in the hand or foot [1]. Macrodactyly is a rare presentation of TS with overgrowth of the soft tissue, undulating periosteal reaction and cystic foci in the phalanges and metacarpal bones [2]. Lesions on the hand are characteristic and are more prominent in older patients.

\section{References}

1. Umeoka S, Koyama T, Miki Y et al (2008) Pictorial review of tuberous sclerosis in various organs. Radiographics 28:e32

2. Sahoo B, Handa S, Kumar B (2000) Tuberous sclerosis with macrodactyly. Pediatr Dermatol 17:463-465 